\title{
Diagnóstico da cadeia produtiva do morango dos agricultores familiares do Distrito Federal
}

Diagnosis of strawberry's production chain from Federal District family farmers

Kever Bruno Paradelo Gomes, Instituto Federal de Brasília - Campus Gama, kever.gomes@ifb.edu.br Gabriel Henrique Horta Oliveira, Instituto Federal de Brasília - Campus Gama, gabriel.horta@ifb.edu.br Josué Pires Carvalho, Instituto Federal de Brasília - Campus Gama, josue.carvalho@ifb.edu.br David Frederik da Silva Cavalcante, Instituto Federal de Brasília - Campus Gama, david.cavalcante@ifb.edu.br Markus Emílio Villa-Real, Curso Técnico em Agronegócio do Instituto Federal de Brasília - Campus Gama, markusvillareal@yahoo.com.br

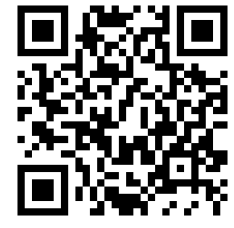

O morango é originário do cruzamento natural de espécies provenientes da América do Norte (Fragaria virginiana) e do Chile (Fragaria chiloenses), sendo este pertencente à família das Rosáceas e gênero Fragaria. A introdução do cultivo do morangueiro no Brasil ocorreu por volta da década de 1950, no sul do estado de Minas Gerais (Moretti, 2008), expandindose em diferentes tipos de climas e solos até sua chegada ao Distrito Federal (DF). A inserção dessa cultura no DF obteve sucesso em razão da altitude da região (em torno de $1.000 \mathrm{~m}$ ) e das condições climáticas, em que ocorrem temperaturas mais altas no verão seguido de um inverno ameno e seco, que favorece a floração, frutificação e qualidade dos frutos (Henz, 2010).

Em 2010, a produção foi de 5 mil toneladas, com uma produtividade de 40 t ha-1 (Costa \& Queiroz, 2010). No mesmo ano foram cultivados 70 ha de morango na região de Brazlândia, sendo necessário cerca de 5 milhões de mudas. Segundo dados da Festa do Morango de Brasília (2010), grande parte da produção local é exportada para Estados próximos, como Goiás, Tocantins, Maranhão e Piauí. A comercialização de morangos no estado in natura responde por cerca de $90 \%$ do 
total comercializado (Antunes \& Reisser Junior, 2007), sendo os restantes comercializados na forma de geleias, iogurtes, bolos, entre outros.

A cultura do morango desempenha importante papel na agricultura familiar, podendo ser explorada em pequenas faixas de terra quando comparada com outros produtos agrícolas. Segundo Madail (2008), o morango é uma cultura de uso intensivo de mão de obra: em torno de cinco pessoas ocupadas por hectare produtivo.

Nos últimos anos a cultura do morangueiro sofreu a introdução de novas cultivares e outras técnicas de cultivo, possibilitando um aumento de produção e qualidade, que tornaram o morango uma alternativa econômica viável para os produtores rurais do DF. Tendo o fator tecnológico em foco e com o intuito de aumentar a competitividade do morango do DF, 0 produtor rural ou sua entidade organizacional deve conhecer profundamente o seu negócio, procurando definir bem o mercado em que irá atuar, e buscar adaptar as condições de sua propriedade para atendê-lo. Portanto, o produtor rural com uma visão empreendedora precisa buscar, constantemente, informações atualizadas que auxiliem as tomadas de decisão, pois o agronegócio, para ser bem gerenciado, requer do produtor rural perfeito conhecimento do que ocorre "antes, dentro e fora da porteira", para que tenha condições de acompanhar o desenvolvimento e evitar a escassez de recursos, a fim de poder competir no mercado consumidor.

Considerando o explanado anteriormente, o presente trabalho teve como objetivo diagnosticar a cadeia produtiva do morango nas unidades de produção familiar, analisando a percepção desses produtores quanto aos vários aspectos, principalmente econômicos, que envolvem o sistema de produção do morango.

\section{Material e Métodos}

No presente trabalho adotou-se a estratégia metodológica baseada na aplicação de técnicas de coleta, processamento, análise e síntese de informação. 0 projeto foi desenvolvido na zona rural de Brazlândia, especificamente na região de Alexandre Gusmão, a 61 km do Instituto Federal de Brasília - Campus Gama, em unidades de produção do tipo empresa familiar dedicada ao cultivo do morango.

A maior parte do esforço na execução da metodologia foi aplicada na coleta de informação. Inicialmente foi realizado contato com a Empresa de Assistência Técnica Local (Emater-DF), objetivando a caracterização inicial do perfil dos produtores rurais, mapeamento das unidades de produção e maior aceitabilidade dos produtores durante a visitação dos pesquisadores e alunos. Nessa etapa, foram identificados os principais produtores que apresentavam dificuldades na aplicação de tecnologia para obter melhor viabilidade no seu negócio, bem como aqueles de baixa alfabetização.

A qualidade da informação obtida depende da elaboração de um formulário que cubra os temas pertinentes aos objetivos da pesquisa. Sendo assim, versões preliminares baseadas no estudo do Ministério do Desenvolvimento Agrário (2011) foram encaminhadas à Emater para análise e sugestões, resultando em modificação de questões, alterações em sequências e inclusão de novas questões. 0 questionário pode ser visualizado no Anexo I.

0 questionário ou formulário de entrevista consiste de questões fechadas a uma amostra estatisticamente representativa do universo de propriedades rurais, consistindo de 16 entrevistas de um total de 25 unidades de produção. As entrevistas foram conduzidas pelos professores orientadores e pelos estudantes, após prévio treinamento. As visitas ocorreram aos sábados.

A informação coletada foi processada em um banco de dados eletrônicos pelos estudantes sob supervisão dos orientadores. Após a inserção dos resultados no banco de dados, foi realizada análise estatística (descritivas e inferenciais), baseada no método de análise de conteúdo (BARDIN, 1977).

\section{Resultados e Discussão}

De acordo com a análise estatística do banco de dados, obtiveram-se os resultados acerca da caracterização do imóvel rural e da caracterização da produção rural. Na caracterização do imóvel rural, três características foram avaliadas: 0 tamanho da propriedade rural, recursos naturais e tipos de construções que constituem o imóvel rural. Os resultados dessas três características podem ser visualizados, respectivamente, nas Tabelas 1, 2 e 3.

Tabela 1: Caracterização da área das propriedades rurais e a área destinada ao cultivo do morangueiro.

\begin{tabular}{|l|c|c|c|c|}
\hline $\begin{array}{l}\text { Propriedade } \\
\text { rural }\end{array}$ & $\begin{array}{c}<1 \\
\text { ha }\end{array}$ & $\begin{array}{c}>1 \text { ha e } \\
<5 \text { ha }\end{array}$ & $\begin{array}{c}>5 \text { ha e } \\
<10 \text { ha }\end{array}$ & $\begin{array}{c}>10 \\
\text { ha }\end{array}$ \\
\hline $\begin{array}{l}\text { Número } \\
\text { de imóveis } \\
\text { rurais }\end{array}$ & - & 6 & 9 & 1 \\
\hline $\begin{array}{l}\text { Número } \\
\text { de imóveis } \\
\text { rurais e } \\
\text { respectivas } \\
\text { áreas para } \\
\text { produção de } \\
\text { morango* }\end{array}$ & 7 & 9 & - & - \\
\hline
\end{tabular}

* área ocupada com a produção do morango no período da entrevista (06/2012). 
Tabela 2: Caracterização dos recursos naturais das propriedades rurais.

\begin{tabular}{|c|l|c|c|}
\hline $\begin{array}{c}\text { Recursos } \\
\text { naturais }\end{array}$ & \multicolumn{1}{|c|}{ Sim } & \multicolumn{2}{|c|}{ Não } \\
\hline \multirow{2}{*}{ Água } & $\begin{array}{l}\text { Fonte alternativa de } \\
\text { água no imóvel }\end{array}$ & 4 & $2 *$ \\
\cline { 2 - 4 } & $\begin{array}{l}\text { Poço artesiano no } \\
\text { imóvel }\end{array}$ & 10 & - \\
\hline $\begin{array}{c}\text { Abastecimento } \\
\text { de água }\end{array}$ & $\begin{array}{l}\text { Suficiente para produ- } \\
\text { ção e consumo }\end{array}$ & 12 & 4 \\
\hline Solo & Férteis & 9 & 7 \\
\hline
\end{tabular}

* Fonte de água fora da propriedade rural.

Tabela 3: Caracterização da infraestrutura das propriedades rurais.

\begin{tabular}{|l|c|c|c|}
\hline $\begin{array}{l}\text { Infraestrutu- } \\
\text { ral do imóvel }\end{array}$ & $\begin{array}{c}\text { Não } \\
\text { constru- } \\
\text { ída }\end{array}$ & $\begin{array}{c}\text { Parcialmen- } \\
\text { te constru- } \\
\text { ída }\end{array}$ & $\begin{array}{c}\text { Totalmente } \\
\text { construída }\end{array}$ \\
\hline $\begin{array}{l}\text { Residência } \\
\text { familiar }\end{array}$ & - & 5 & 11 \\
\hline $\begin{array}{l}\text { Sanitário na } \\
\text { residência }\end{array}$ & - & - & 16 \\
\hline $\begin{array}{l}\text { Silos ou de- } \\
\text { pósito para } \\
\text { produção }\end{array}$ & 8 & 6 & 2 \\
\hline $\begin{array}{l}\text { Cercas } \\
\text { carregadores } \\
\text { internos }\end{array}$ & - & 4 & 4 \\
\hline
\end{tabular}

Pela Tabela 1, pode-se notar que 37,5 \% dos imóveis possuem área entre 1 e 5 hectares, ao passo que $56,25 \%$ são de imóveis entre 5 e 10 hectares, restando apenas 6,25\% com imóveis apresentando área total acima de 10 hectares. Avaliando especificamente a produção de morangos, apesar de $62,5 \%$ dos imóveis terem uma área maior que 5 hectares, os produtores não destinam a maior parte de sua área para o cultivo do morangueiro. Ademais, em geral, a região analisada possui basicamente toda a área plana, não havendo, dessa maneira, problemas de erosão nem de compactação do solo, principalmente pela ausência de uma pecuária extensiva.

Do ponto de vista dos recursos naturais (Tabela 2), tem importância primordial o suprimento de água às propriedades rurais. Dessa forma, objetivou-se abordar na pesquisa os temas relacionados com a origem da água disponível para a produção agrícola (interna ou externa ao imóvel) e a suficiência do abastecimento. Poços artesianos cavados adequadamente em regiões de chuvas regulares e com longo período de seca são extremamente importantes para sustentabilidade do negócio rural.
Nota-se na Tabela 2 que há a prevalência do sistema de poços artesianos nas propriedades $(62,5 \%)$, sendo o restante devido às fontes alternativas de água, tais como minas, córregos, dentre outros. Com relação à quantidade suficiente, tanto para a produção quanto para o consumo familiar, nota-se que $25 \%$ dos produtores indicaram ser insuficientes, sendo este um importante gargalo à produção e qualidade. Analisando ainda a Tabela 2, apenas 9 dos 16 proprietários indicaram que o solo de suas propriedades são férteis ao cultivo do morangueiro, sendo necessário investimentos em insumos para correção e fertilização do solo.

Com relação à infraestrutura dos imóveis, verifica-se pela Tabela 3 que as estruturas atuais, tanto das residências quanto dos sanitários, são satisfatórias, restando apenas 5 residências parcialmente construídas. Devido ao fato de as propriedades rurais serem basicamente urbanas, observa-se a facilidade do escoamento da produção com estradas de fácil acesso. Outro fator observado é a inexistência de cercas, característica que pode ser explicada pela não existência de produção pecuária leiteria na região.

Incentivos governamentais deverão ser realizados, na forma de programas de empréstimo, para que silos e cercas possam ser viabilizadas, já que essas estruturas ocorrem plenamente em poucas propriedades. Especificamente com relação aos silos e depósitos, a falta dessa estrutura de modo adequado acarreta perdas quantitativas e qualitativas do morango, uma vez que a falta de silos e depósitos adequados implica a perda de poder de negociação da venda dos morangos, visto que estes devem ser vendidos necessariamente após a colheita, caso contrário os frutos se tornarão inaptos para o consumo em razão de seu baixo período de vida de prateleira.

Na caracterização da produção rural, nove características foram avaliadas: a produção para alimentação familiar, rendimento da produção do morango, adoção de insumos na produção de morango, produtividade, fatores críticos de desempenho da cadeia produtiva do morango, mão de obra, mercado, renda familiar e relação entre despesas e ganhos.

A Tabela 4 demonstra a produção para a alimentação familiar dos produtores de morango da região de Alexandre Gusmão.

Tabela 4: Caracterização da produção para a alimentação familiar.

\begin{tabular}{|l|c|c|}
\hline \multicolumn{1}{|c|}{ Empreendimentos rurais } & Produz & $\begin{array}{c}\text { Não pro- } \\
\text { duz }\end{array}$ \\
\hline $\begin{array}{l}\text { Produção para subsistência } \\
\text { alimentar }\end{array}$ & 9 & 7 \\
\hline $\begin{array}{l}\text { Outra produção vegetal } \\
\text { para o mercado }\end{array}$ & 15 & 1 \\
\hline
\end{tabular}


Tratando-se de empreendimentos de agricultura familiar, é de supor que parte considerável do esforço produtivo seja direcionada para suprir as necessidades do grupo familiar, que representou $56,25 \%$ dos casos (Tabela 4). Outro ponto importante nesses empreendimentos rurais é a produção voltada para 0 mercado, com o objetivo de gerar renda e ganhar sustentabilidade, no sentido de poder ser protagonista da sua própria existência. Esse fato é percebido pela elevada ocorrência nas propriedades rurais $(93,75 \%)$. No caso de outros produtos produzidos na propriedade destinados ao mercado além do morango, os mais citados foram: pimentão, beterraba, abobrinha, feijão, vagem, jiló, abóbora, pepino, alface e folhosas em geral. A Tabela 5 relata o rendimento da produção do morango dos imóveis rurais.

Tabela 5: Caracterização do rendimento da produção do morango das propriedades rurais.

\begin{tabular}{|c|c|c|}
\hline $\begin{array}{c}\text { Rendimento do cultivo do moran- } \\
\text { gueiro }\end{array}$ & Sim & Não \\
\hline Suficiente para o sustento familiar & 11 & 5 \\
\hline
\end{tabular}

Nota-se que grande parte dos agricultores relatou que a exploração da cultura do morangueiro é suficiente para o sustento familiar, indicando assim a viabilidade da cadeia agroindustrial do morango na região. No entanto, investimentos em tecnologia e insumos, principalmente na aquisição de mudas, deverão ser feitos no intuito de aumentar a renda dos produtores e atingir 100\% de rendimento suficiente para o sustento familiar.

Em conjunto com o rendimento das áreas exploradas para o cultivo do morangueiro, pode-se denotar a caracterização da mão de obra presente nas propriedades rurais. Foi possível verificar que há uma predominância do trabalho familiar nas lavouras de morango, ou seja, traços da agricultura familiar. Esse fato pode ser uma explicação para a suficiência indicada do rendimento da família, uma vez que a utilização do trabalho familiar acarreta menos despesas com contratação de mão de obra. Entretanto, no tocante à fase da colheita e póscolheita, praticamente todos os produtores entrevistados apontaram a necessidade de contratação da mão de obra externa durante esse período.

A Tabela 6 denota o grau de adoção de insumos na produção dos morangos.

Tabela 6: Caracterização dos insumos utilizados na produção do morango nas propriedades rurais

\begin{tabular}{|c|c|c|}
\hline Insumos & Utiliza & Não utiliza \\
\hline Mudas & 12 & 4 \\
\hline Agrotóxicos & 16 & - \\
\hline Defensivos agrícolas & 16 & - \\
\hline
\end{tabular}

Pela análise da Tabela 6, é notório o largo uso de insumos na produção do morango pelos agricultores. No entanto, $25 \%$ dos produtores relataram que não utilizam mudas de boa qualidade. Uma possível explicação para esse fato reside na dificuldade de aquisição de mudas, uma vez que grande parte das mudas são adquiridas em São Paulo, e uma pequena parte é importada do Uruguai, onerando o custo e, por conseguinte, o valor do produto final. Ademais, os produtores entrevistados relataram que as mudas adquiridas do estado de São Paulo são relativamente fracas, susceptíveis ao ataque de pragas e doenças, havendo um número razoável de mortalidade.

No sistema de produção, acerca da aplicação de agrotóxicos e defensivos agrícolas, constata-se a falta de preocupação em utilizar os equipamentos de proteção individual (EPI) no dia a dia, apesar da divulgação de informações a respeito das consequências da sua não utilização frequentemente realizada pela Emater. Nesse sentido, é importante ressaltar 0 potencial de produção do morango orgânico, que se destaca por possuir maior impacto, procura e valor no mercado. Para o alcance dessa produção, é necessário, no entanto, a realização de palestras e consultorias que orientem o agricultor quanto às vantagens e às tecnologias associadas ao cultivo. A Tabela 7 relata a percepção dos produtores quanto à produtividade de suas propriedades.

Tabela 7: Caracterização da produtividade do morango nas propriedades rurais.

\begin{tabular}{|c|c|}
\hline Produtividade & Número de imóveis \\
\hline Baixa & 3 \\
\hline Média & 11 \\
\hline Alta & 2 \\
\hline
\end{tabular}

A maioria dos agricultores relatou que a produtividade do morango em suas respectivas propriedades é de nível médio. Essa afirmação pode ser explicada pelos insumos utilizados na produção. Segundo os produtores, as mudas não são de boa qualidade, apresentando alta incidência de pragas e doenças, tendo assim perdas consideráveis na produção total e consequentemente na produtividade do imóvel.

Diferentes fatores críticos do desempenho da cadeia produtiva do morango foram externados pelos agricultores. Esses fatores estão apresentados na Tabela 8.

Tabela 8: Caracterização dos fatores críticos de desempenho da cadeia produtiva do morango.

\begin{tabular}{|l|c|}
\multicolumn{1}{|c|}{ Fatores limitantes } & Ocorrências \\
\hline Má qualidade das mudas & 10 \\
\hline Presença de pragas e doenças & 10 \\
\hline Deficiência mineral & - \\
\hline $\begin{array}{l}\text { Perdas em decorrência do perí- } \\
\text { odo seco }\end{array}$ & 2 \\
\hline Falta de mão de obra & 9 \\
\hline Falta de assistência técnica & - \\
\hline
\end{tabular}


Dentre os fatores indagados aos produtores, destacaramse a má qualidade das mudas, a presença de pragas e doenças e a falta de mão de obra, fatores já explanados anteriormente. No entanto, nesta etapa do questionário, houve maior preocupação por parte dos entrevistados com relação à falta e à alta rotatividade da mão de obra local. Os produtores entrevistados indicaram que ocorrem altos custos com capacitação de funcionários para atuar na colheita e pós-colheita, no entanto há alta incidência de posterior saída desses funcionários, principalmente pela concorrência com as empresas de construção civil da região.

A caracterização da comercialização do morango pelos produtores está apresentada na Tabela 9 abaixo.

Tabela 9: Caracterização do modo de comercialização empregado pelos produtores.

\begin{tabular}{|l|c|c|c|}
\hline $\begin{array}{c}\text { Tipo de comercia- } \\
\text { lização }\end{array}$ & $\begin{array}{c}\text { Pequena } \\
\text { parte }\end{array}$ & $\begin{array}{c}\text { Grande } \\
\text { parte }\end{array}$ & $\begin{array}{c}\text { Toda a } \\
\text { produção }\end{array}$ \\
\hline $\begin{array}{l}\text { Programa de aqui- } \\
\text { sição de alimentos }\end{array}$ & 5 & - & - \\
\hline $\begin{array}{l}\text { Comercialização } \\
\text { própria }\end{array}$ & - & 7 & - \\
\hline Intermediários & - & - & 20 \\
\hline
\end{tabular}

Nesta arguição, os entrevistados puderam indicar mais de uma fonte de comercialização do seu produto. Verifica-se que a comercialização é dominada pelos intermediários, que podem, às vezes, absorver a maior parte dos lucros. A comercialização própria desses agricultores está crescendo, porém de forma informal, conforme se pode observar pelo aumento de pontos de vendas em estradas e até mesmo nas quadras urbanas de quase todo o DF.
No âmbito da agricultura familiar, e neste caso com referência ao local da pesquisa, foi possível identificar a presença de um novo status no meio rural: a passagem do padrão de agricultor para o de pequenos empresários rurais. A capacidade de gerar renda a partir da comercialização da produção agrícola é um dos pré-requisitos para o desenvolvimento dos empreendimentos e para a elevação da qualidade de vida na comunidade. 0 estabelecimento de uma boa relação sustentável e rentável com o mercado é uma das grandes dificuldades de gestão dos empreendimentos familiares. Nesse sentido, percebeu-se a importância da presença da Emater-DF nesta região, cuja assistência ameniza esse gargalo no desenvolvimento de parcerias e cooperativismo rural.

A renda familiar pode ser composta por diversas fontes, cuja importância relativa pode diferir entre os membros de uma mesma comunidade. Aos entrevistados foi perguntado quais são suas principais fontes de renda e solicitado que as classificassem por ordem de importância, em termos de sua contribuição para os ganhos da família. A maioria indicou como de maior importância a venda dos produtos produzidos na propriedade familiar como principal fonte de renda. Outras rendas alternativas também foram apresentadas, principalmente ganhos do trabalho fora da propriedade, sendo para o agricultor essencial para melhorar sua qualidade de vida.

A percepção da rentabilidade da propriedade pelos produtores entrevistados pode ser visualizada na Figura 1.

Pela Figura 1 pode-se verificar que os produtores consideram que os empreendimentos rurais são viáveis no seu modelo de produção, porém que ainda é necessário avançar alguns elos da cadeia produtiva, principalmente na parte dos insumos e comercialização.

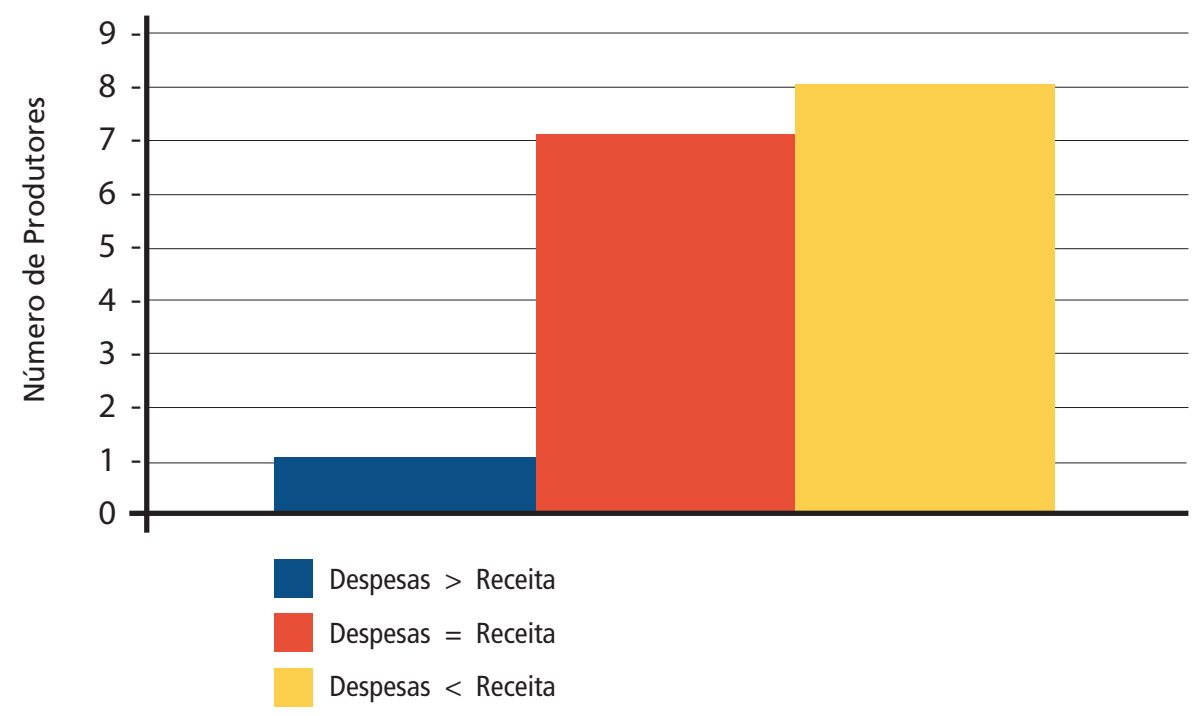

Figura 1: Percepção dos agricultores sobre a rentabilidade da produção do morango. 


\section{CONCLUSÃO}

Constatou-se que os principais fatores críticos para o desempenho da cadeia produtiva do morango são a falta de mão de obra, principalmente no período de colheita, e a inexistência de produção de mudas no local, o que eleva o custo no elo dos insumos, sendo grande parte importada de outros estados e até mesmo de outros países. Foi observado ainda que a falta de uma cooperativa dificulta a comercialização dos produtores, que, devido às dificuldades de logística, acabam por vender seu produto a atravessadores, fato que acarreta a perda de poder aquisitivo dos produtores e 0 aumento do custo do produto para o consumidor final.

Sugerem-se ainda estudos de demanda para que se conheça melhor o potencial de mercado desse produto, em especial o morango orgânico, que pode se tornar um grande fator de competitividade, gerando um considerável aumento de renda.

Foi possível verificar a proatividade do trabalho da Emater-DF, entidade que vem desenvolvendo um projeto evolutivo e participativo na comunidade, auxiliando no desenvolvimento da cooperativa dos produtores de morango.

\section{AgRAdECIMENTOS}

À Pró-Reitoria de Pesquisa e Inovação do Instituto Federal de Brasília pelo suporte financeiro na execução desta pesquisa, por meio do Edital 35/PRPI/RIFB/2011.

\section{REFERÊNCIAS}

ANTUNES, L. C.; REISSER JUNIOR, C. Produção Integrada de Morango: oportunidade de mercado. In: SIMPÓSIO NACIONAL DO MORANGO, 4.; ENCONTRO SOBRE PEQUENAS FRUTAS E FRUTAS NATIVAS DO MERCOSUL, 3. , 2008, Pelotas (RS). Palestras \& resumos... Pelotas: Embrapa Clima Temperado, 2008.

Fragole, i Produttori Brasiliani Mirano all'Esportazione in Europe. Frutticoltura. Bologna, v. 69, n. 5, p. 60-64, 2007.

BARDIN, L. Análise de conteúdo. Edições 70. Lisboa, 1977.

COSTA, R; QUEIROZ, A. Brazlândia tem safra recorde de morango. Disponível em: www.festadomorangodf.com. br/2010. Acessado em: 15 de setembro de 2012

FESTA DO MORANGO DE BRASÍLIA. 15a Festa do Morango de Brasilia. Disponível em: www.festadomorangodf.com. br/2010. Acessado em: 15 de setembro de 2012.
HENZ, G. P. Desafios enfrentados por agricultores familiares na produção de morango no Distrito Federal. Horticultura Brasileira, v. 28, n. 3, p. 260-265, 2010.

MADAIL, J. C. M. A. Economia do Morango. Embrapa Clima Temperado. In: SIMPÓSIO NACIONAL DO MORANGO, 4.; ENCONTRO SOBRE PEQUENAS FRUTAS E FRUTAS NATIVAS DO MERCOSUL, 3., 2008, Pelotas (RS). Palestras \& resumos... Pelotas: Embrapa Clima Temperado, 2008.

MINISTÉRIO DO DESENVOLVIMENTO AGRÁRIO, Secretaria de Reordenamento Agrário, Coordenação Geral de Planejamento, Monitoramento e Avaliação, Projeto Crédito Fundiário e Pobreza Rural:VIEIRA, L.F.; CASTRO, A.M.G. de; LIMA, S.M.V. Perfil dos beneficiários do Programa Nacional de Crédito Fundiário: consolidação da Agricultura Familiar. Brasília, Ministério do Desenvolvimento Agrário, 2011. 132 p.

MORETTI, C. L. Manuseio pós-colheita, compostos funcionais e logística de distribuição de morangos. In: SIMPÓSIO NACIONAL DO MORANGO, 4.; ENCONTRO SOBRE PEQUENAS FRUTAS E FRUTAS NATIVAS DO MERCOSUL, 3., 2008, Pelotas (RS). Palestras \& resumos... Pelotas: Embrapa Clima Temperado. 